\title{
RESVERATROL EM ESPÉCIES DE COCCOLOBA (POLYGONACEAE): COCCOLOBA PARIMENSIS E COCCOLOBA RAMOSISSIMA
}

\author{
Camila dos Santos Silva ${ }^{1}$; Efigênia de Melo $^{2}$; Flávio França ${ }^{3}$ e Hugo Brandão \\ 1. Bolsista PROBIC/UEFS, Graduanda em Farmácia, Universidade Estadual de Feira de Santana, e-mail: \\ mila.css@hotmail.com \\ 2. Efigênia de Melo, Departamento de Ciências Biológicas, Universidade Estadual de Feira de Santana, e-mail: \\ efidemelo@hotmail.com \\ 3. Flavio França, Departamento de Ciências Biológicas, Universidade Estadual de Feira de Santana, e-mail: \\ franca.flavio@gmail.com \\ 4. Hugo Brandão, Departamento de Saúde, Universidade Estadual de Feira de Santana, e-mail: hugo@uefs.br
}

PALAVRAS-CHAVE: Polygonaceae; Coccoloba; Resveratrol.

\section{INTRODUÇÃO}

Resveratrol é um polifenol relacionado a benefícios na saúde humana. É uma substância encontrada em várias espécies vegetais, sendo sua fonte mais abundante as uvas (Vitis, Vitaceae), em grande quantidade na casca da uva e no vinho tinto, porém também com ocorrência na família Polygonaceae, como em Polygonum cuspidatum (DONG-GENG; WEN-YING; GUANG-TONG, 2013). Contudo a pesquisa desta substância em espécies de Coccoloba, gênero nativo de Polygonaceae, muito comum na região do recôncavo baiano, ainda é incipiente e não conclusiva.

O resveratrol é sintetizado naturalmente na planta sob duas formas isômeras: transresveratrol (trans-3,5,4'-trihidroxiestilbeno) e cis-resveratrol (cis-3,5,4'-trihidroxiestilbeno. $\mathrm{O}$ isômero transresveratrol é convertido para cis-resveratrol em presença da luz visível, pois esta forma é mais estável.

O trans-resveratrol possui estrutura molecular similar à do estrogênio sintético, portanto tem propriedades farmacológicas semelhantes às do estradiol, principal estrogênio humano natural. Esta substância vem sendo há muito tempo utilizada no tratamento de arteriosclerose, doenças inflamatórias e alérgicas, com atividade antiagregação plaquetária, antioxidante e redutora de triglicerídeo, sendo também testada no tratamento de câncer (DAVID et al, 2007).

Coccoloba parimensis é arbusto escandente ou liana, ramos apicais glabros, casca fissurada, folhas ovais breve-acuminadas ou cordadas, racemos menores que as folhas. Flor com unido até $1 / 2$ glabro ou pubérulo; flor estaminada $1,5-2 \mathrm{~mm}$; flor andrógina 2-3mm; flor pistilada 2-3 mm; hipanto infundibuliforme ou campanulado; estigmas captados; nectários presentes. Acrossarco com perianto frutífero 5-10 mm; oval ou subgbordoso; coriáceo, glabro; bordos aderidos na maturidade; pericarpo subgbordoso; ápice mamilado; pedúnculos frutíferos 3-5 mm, espessados. Coccoloba ramosissima é arbusto ereto, ramos apicais glabros ou pubérbulos, casca lisa, lenticelas arredondadas. Folhas elíptico-ovais pequenas, com base arredondada ou subcordada, coriácea, glabra, pecíolo curto e pubérulo. Flor com perianto unido até $1 / 2$ glabro; flor estaminada 1,5-2 mm; flor andrógina $1,5-2 \mathrm{~mm}$; flor pistilada 1-2 $\mathrm{mm}$; hipanto companulado; estigmas lamelado-decurrentes; nectários presentes. Acrossarco com perianto frutífero $2,5 \mathrm{~mm}$, globoso, coriáceo, glabro, bordos livres acima de $1 / 2 \mathrm{ou}$ aderidos na maturação; pericarpo globoso; ápice obtuso-arredondado, pedúnculos frutíferos 25 mm, não espassada (MELO, 2003; SOUZA, 2007).

$\mathrm{Na}$ Bahia, Coccoloba parimensis ocorre em cerrados, caatingas, restingas, matas estacionais, matas ciliares e matas atlânticas. Coccoloba ramosissima ocorre exclusivamente em restingas (MELO, 2003).

Diante do exposto, o trabalho visou verificar a presença de resveratrol em Coccoloba parimensis e Coccoloba ramosissima. 


\section{METODOLOGIA}

\section{Coleta do material vegetal}

As coletas do material vegetal foram realizadas no campus da Universidade do Estado da Bahia (UNEB) de Alagoinhas (BA). O material vegetal coletado foi levado para a Universidade Estadual de Feira de Santana (UEFS).

\section{Secagem do material}

A secagem do material ocorreu no Laboratório de Taxonomia Vegetal da UEFS, onde o material vegetal ficou em bandejas à temperatura ambiente, até que o mesmo estivesse totalmente seco para a continuação dos trabalhos. Após a secagem, cada espécie vegetal foi triturada em liquidificador e separada em embalagens com identificação.

\section{Exposição do material vegetal à radiação Ultravioleta}

O banho de radiação Ultravioleta (UV) aconteceu no Laboratório de Microbiologia da UEFS. O material ficou exposto por 2:30h à radiação UV e cada espécie foi colocada em uma bandeja contendo papéis umedecidos.

\section{Extração}

No primeiro procedimento a obtenção do extrato vegetal foi realizada através da introdução das amostras em Etanol (EtOH), contidas no Erlenmeyer, em uma cuba com ultrassom por quarenta minutos. A extração do material no segundo procedimento foi realizada através do método de maceração. Na maceração o material ficou em contato com o álcool a $98^{\circ}$ dentro do Erlenmeyer por quinze dias.

Após cada processo de extração, foi realizada a filtração do extrato com o solvente com a utilização de algodão em funil. Obtidos os materiais líquidos, os mesmos foram levados para a capela com exaustor, no primeiro procedimento, e para a estufa, no segundo procedimento no Laboratório de Microbiologia da UEFS, para a evaporação do solvente.

\section{Preparo da amostra para Cromatografia Líquida de Alta Eficiência}

No Laboratório de Fitoquímica da UEFS, foram pesados em balança analítica 0,05 gramas do extrato de cada espécie e dissolvidos em $1 \mathrm{~mL}$ da fase móvel (ácido acético 0,7\% + acetonitrila) e filtrados por bomba de ar.

\section{Análises Cromatográficas}

A busca pelo resultado esperado se baseou em primeiramente realizar a análise cromatográfica por Cromatografia Líquida de Alta Eficiência (CLAE) do padrão de transresveratrol utilizado no trabalho para a detecção do seu tempo de retenção no aparelho HPLC (do inglês High Performance Liquid Chromatography), em minutos (MALVIYA et al, 2010), e seu espectro de absorção UV, também no Laboratório de Fitoquímica da UEFS.

Após a detecção do tempo de retenção do resveratrol, seguiram-se as análises cromatográficas nas amostras dos extratos vegetais das duas espécies, em triplicata, para que fosse analisado se seria apresentado algum pico com o mesmo tempo de retenção ou tempo próximo ao do resveratrol.

\section{RESULTADOS E DISCUSSÃO}

Os resultados obtidos com as análises cromatográficas se deram através da comparação dos tempos de retenção e dos espectros no ultravioleta (UV) do padrão de resveratrol e das amostras de Coccoloba parimensis e Coccoloba ramosissima com e sem a exposição de UV. O intervalo de tempo entre a coleta do material vegetal, secagem, maceração e preparação da amostra até as análises pode ter sido considerado um fator que acarretou em possíveis alterações das moléculas presentes nas folhas estudadas.

O primeiro método utilizado no HPLC para a análise cromatográfica das amostras do material vegetal que recebeu radiação UV foi baseado na detecção do padrão do resveratrol com o tempo de retenção em 5,6 minutos. Neste método nenhuma das amostras apresentou 
picos com tempo de retenção igual ou próximo ao do padrão. Na segunda fase de testes, foi necessária a mudança do método, pois houve o aparecimento de vários picos no tempo de retenção do padrão, o que dificultaria a análise. Na escolha do novo método para amostras em que o material vegetal não recebeu radiação UV, o padrão do resveratrol teve seu pico com tempo de retenção em 27,4 minutos, como mostrado no cromatograma na Figura 1. Para estes testes, apenas a Coccoloba ramosissima representou um pico com tempo de retenção aproximadamente igual ao do padrão.

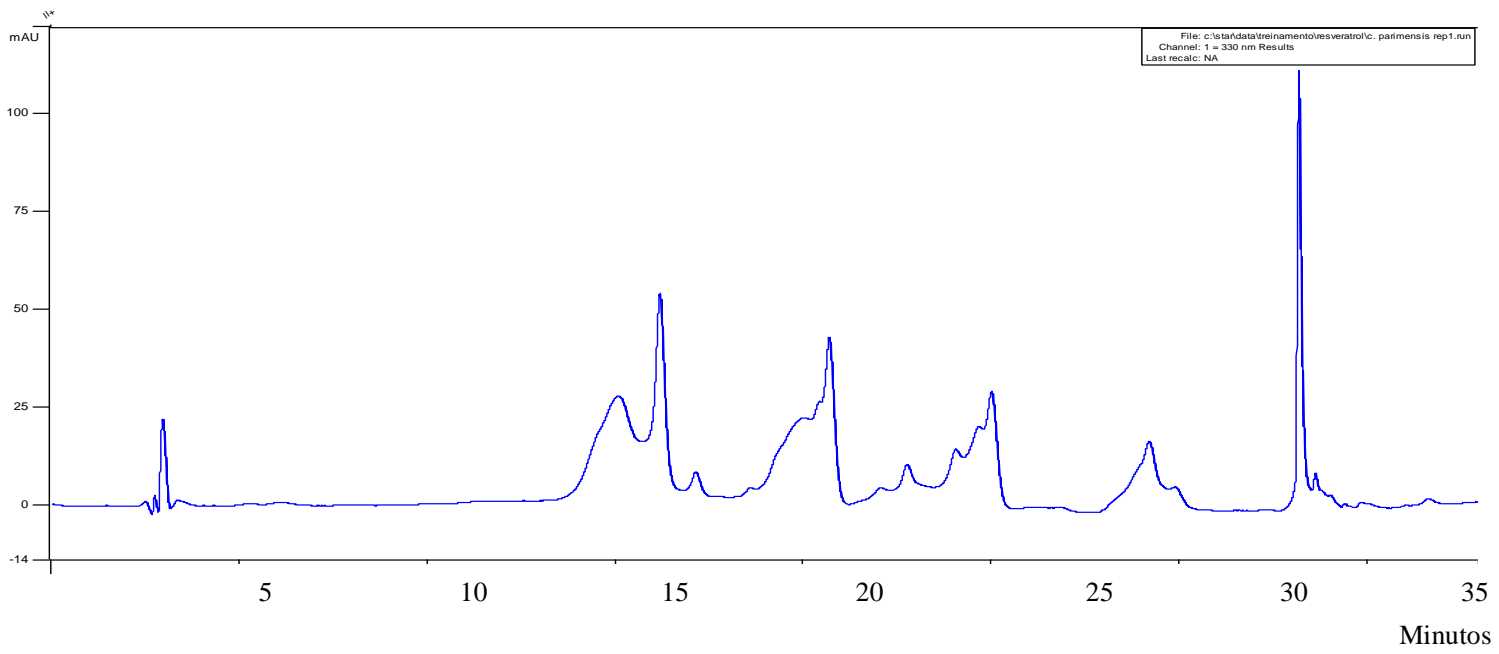

Figura 1: Cromatograma ilustrativo de amostra a 280nm em CLAE. Coccoloba parimensis sem UV

Dentre os picos apresentados pelas amostras da Coccoloba ramosissima que não receberam banho de UV, foi detectado um pico com tempo de retenção de 27,5 minutos, sendo aproximadamente igual ao tempo de retenção do resveratrol (27,4 minutos), tendo uma diferença muito relevante que pode ser justificada pela complexidade da amostra, o que indica a possibilidade da presença da molécula procurada na espécie em questão. A presença do resveratrol na amostra não pode ser completamente confirmada pelo fato da concentração da substância detectada ter sido baixa, o que leva a uma diferença no espectro de absorção, exigindo mais aprofundamento em testes para a maior confirmação.

Além disso, foi possível também perceber que o mesmo pico apresentou espectro de absorção muito próximo ao espectro do resveratrol, sendo que no espectro de resveratrol os comprimentos foram de $223.77 \mathrm{~nm}$ (nanômetros) e $316.75 \mathrm{~nm}$; e na amostra de Coccoloba ramosissima, os comprimentos foram de $244.64 \mathrm{~nm}$ e $316.84 \mathrm{~nm}$ relacionando o comprimento das duas bandas, como mostrado nas figuras 2 e 3 , respectivamente.

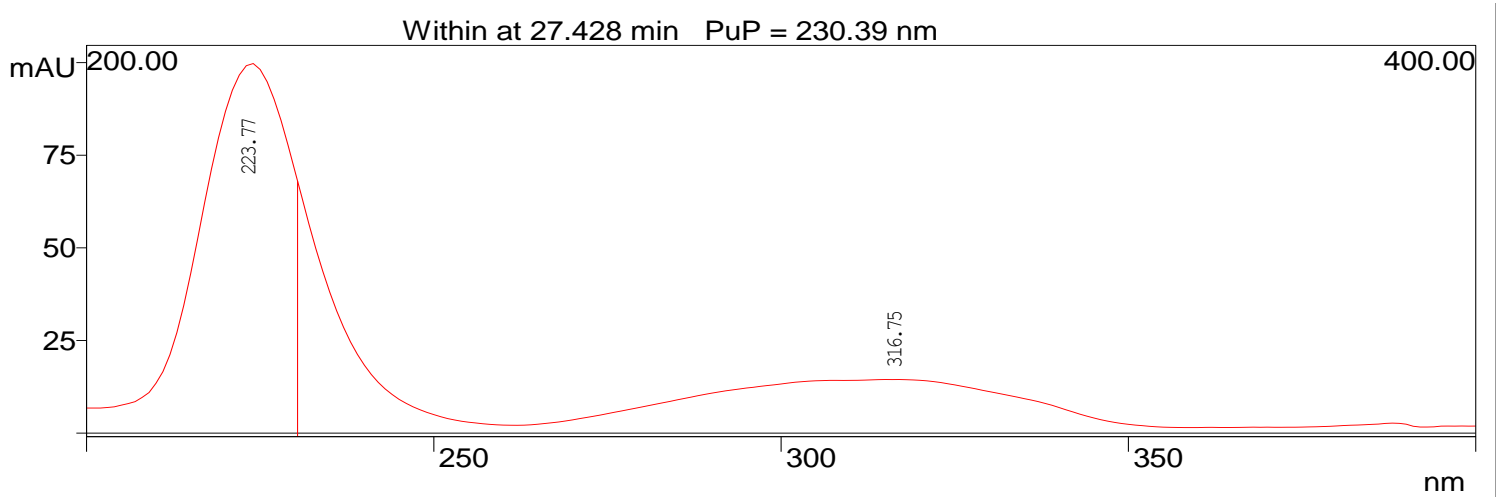

Figura 2: Espectro de UV padrão resveratrol 


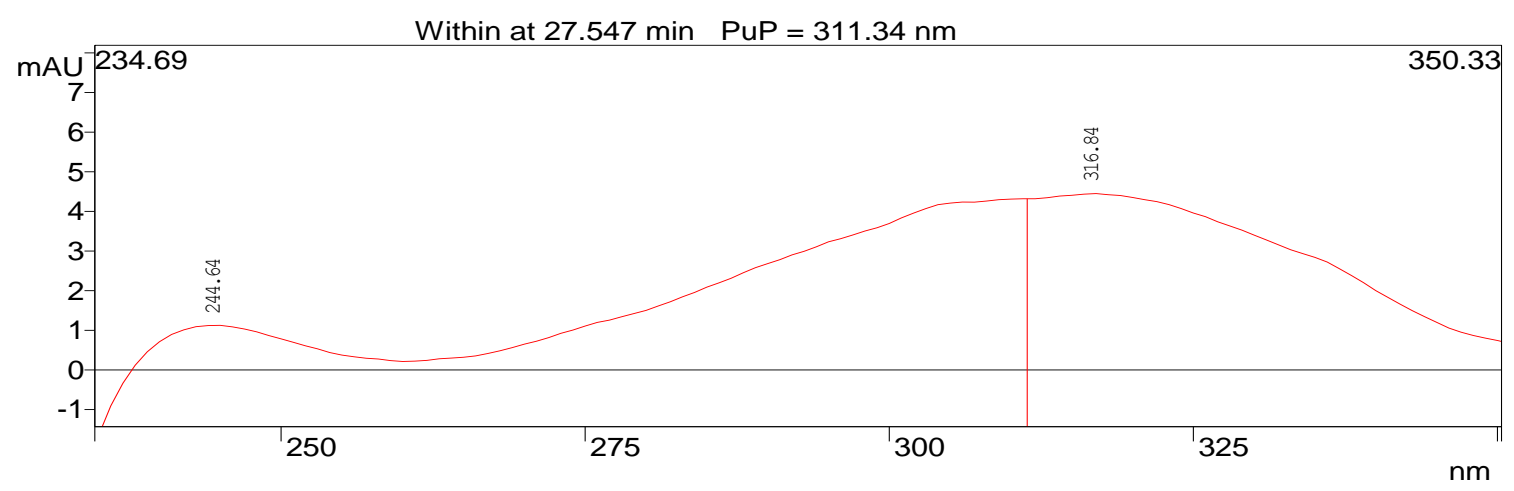

Figura 3: Espectro de UV amostra Coccoloba ramosissima

\section{CONSIDERAÇÕES FINAIS}

De acordo com o presente trabalho, conclui-se que as amostras coletadas de Coccoloba parimensis não apresentam resveratrol, enquanto que as amostras de Coccoloba ramosissima apresentam forte possibilidade de possuírem resveratrol, contudo mais testes são necessários para a confirmação da presença dessa substância na ultima espécie.

Dessa forma, os dados obtidos poderão servir como suporte para o desenvolvimento de novos trabalhos na área, que possam aprofundar e complementar os resultados encontrados, podendo ser exploradas outras partes da planta, pois o mesmo contribui com a quimiossistemática do gênero estudado.

\section{REFERÊNCIAS}

DAVID, J.; DAVID, J.; SANTOS, V.; SANTOS, M.; MOTA, M. Resveratrol: ações e benefícios para a saúde humana. Diálogos e Ciência, v. 5, n.10, p. 1-11, 2007.

DONG-GENG W.; WEN-YING L.; GUANG-TONG C. A simple method for the isolation and purification of resveratrol from Polygonum cuspidatum. Journal of Pharmaceutical Analuysis, 3(4): 241-247. 2013.

MALVIYA, R.; BANSAL, V.; PAL, O. P.; SHARMA, P. K. High performance liquid chromatography: a short review. Journal of Global Pharma Technology, v. 2, p. 2226, 2010.

MELO, E. Revisão do gênero Coccoloba P. Browne (Polygonaceae). Tese de doutorado. São Paulo: Universidade de São Paulo, 2003.

SOUZA, Vinícuis C.; LORENZI, Harri. Botânica Sistemática. ed. 3. São Paulo, 2007 